\title{
Influence of Anterior Guidance on the Inclination of Horizontal Condylar Guidance in Dentulous Subjects - A Clinical Study
}

\author{
Naresh Shetty ${ }^{1}$, Sanath Shetty ${ }^{2}$, Hasan Sarfaraz ${ }^{3}$, Syed Ghouse Ahmed ${ }^{4}$, Fahad Mohammad ${ }^{5}$ \\ 1, 2, 3, 4, 5 Department of Prosthodontics, Yenepoya Dental College, Mangalore, Karnataka, India.
}

\section{ABSTRACT}

\section{BACKGROUND}

One of the most widely used methods to record horizontal condylar guidance is the use of protrusive interocclusal records. Therefore, this study was done to evaluate the reliability of protrusive interocclusal record with and without the influence of anterior determinant on horizontal condylar guidance among dentulous patients.

\section{METHODS}

Diagnostic impressions of 21 participants were made and casts were poured. Facebow record were obtained and transferred to semi-adjustable articulator. Protrusive interocclusal records were made using Alu-wax. In group 1, protrusive interocclusal records were obtained at incisal edge to edge position (conventional method). In group 2, 3 and 4 protrusive interocclusal records were obtained at a distance of $4 \mathrm{~mm}, 6 \mathrm{~mm}$ and at incisal edge to edge position respectively using a customized flat anterior jig. Programming of the Hanau articulator were done for all the 4 groups. One-way ANOVA test and Pearson's correlation tests were done to compare and correlate horizontal condylar guidance.

\section{RESULTS}

The mean values obtained for flat anterior jig at incisal edge to edge position, at $4 \mathrm{~mm}$ and $6 \mathrm{~mm}$ provided good Pearson correlation values for the right $(\mathrm{R}=0.773, \mathrm{R}=$ $0.779, R=0.632)$ as well as the left side $(R=0.631, R=0.601, R=0.545)$ respectively, on comparison with the conventional incisal edge to edge values. This indicated a positive correlation which was statistically significant.

\section{CONCLUSIONS}

The horizontal condylar guidance is influenced by anterior determinant. Therefore, the reliability of protrusive records is dependent on eliminating the influence of anterior determinant.

\section{KEY WORDS}

Horizontal Condylar Guidance, Anterior Determinant, Protrusive Interocclusal Records
Corresponding Author: Dr. Syed Ghouse Ahmed, Department of Prosthodontics, Yenepoya Dental College, Mangalore, Karnataka, India E-mail:warsishahab@gmail.com

DOI: $10.14260 / j e m d s / 2021 / 424$

How to Cite This Article:

Shetty $N$, Shetty $S$, Sarfaraz $H$, et al. Influence of anterior guidance on the inclination of horizontal condylar guidance in dentulous subjects - a clinical study. J Evolution Med Dent Sci 2021;10(28):20722077, DOI: $10.14260 /$ jemds/2021/424

Submission 01-02-2021, Peer Review 12-05-2021, Acceptance 19-05-2021, Published 12-07-2021.

Copyright (c) 2021 Naresh Shetty et al. This is an open access article distributed under Creative Commons Attribution License [Attribution 4.0 International (CC BY 4.0)] 


\section{BACKGROUND}

Condylar guidance on articulators is an approximate replica of the condylar path in patients and reproduced on the instrument with the help of interocclusal records. Recording horizontal condylar guidance plays a pivotal role in prosthodontic rehabilitation. ${ }^{1}$ Failure in recording condylar guidance angle may lead to extra time spent during fabrication and intraoral occlusal modification at the time of insertion of prosthesis. Further, altering occlusal guidance is considered as one of the factors that might initiate temporomandibular joint problems. ${ }^{2}$

We, clinicians, follow the standard treatment protocol given in the literature, to obtain protrusive records at the incisal edge to edge position to set the horizontal condylar guidance angle. The concept of registering horizontal condylar guidance was introduced by Christensen (1905) using protrusive wax check bites. He suggested recording protrusive interocclusal records by protruding the mandible voluntarily and symmetrically more or less at a distance of 4 to $5 \mathrm{~mm}^{3}$ Posselt, (1968) and Craddock (1949) advocated registering protrusive interocclusal records using wax at a distance of 6 $\mathrm{mm} .4,5$

It is noted that anterior determinants of occlusion like overjet and overbite play a significant role while recording the protrusive interocclusal record. ${ }^{6}$ Also, several authors suggested that the angulation of anterior teeth also determines the horizontal condylar guidance values because we are using anterior teeth as a guide to set protrusive paths. 7,8 Schlosser further stated that the average functional range rarely exceeds $4 \mathrm{~mm}$. The $6 \mathrm{~mm}$ record will hold the articulator mechanism more securely. ${ }^{9}$ However, there is no enough literature on the influence of anterior determinants like overjet, overbite, and angulation of teeth on recording horizontal condylar guidance by protrusive interocclusal records.

Therefore, there was a need to evaluate the reliability of the protrusive interocclusal record to obtain horizontal condylar guidance and also assess the influence of anterior determinants on horizontal condylar guidance among dentulous patients. The null hypothesis was that the protrusive interocclusal records made to record horizontal condylar guidance will not be influenced by anterior guidance in dentulous patients.

\section{Objectives}

1. To evaluate the effect of horizontal condylar guidance angle using protrusive interocclusal records with and without the influence of anterior guidance in dentulous patients.

2. To evaluate the horizontal condylar guidance angle using protrusive interocclusal record at incisal edge to edge position (conventional method).

3. To evaluate the horizontal condylar guidance angle using protrusive interocclusal record at incisal edge to edge position using flat Lucia jig.

4. To evaluate the horizontal condylar guidance angle using protrusive interocclusal record at $4 \mathrm{~mm}$ distance from maximum intercuspation position using flat Lucia jig.

5. To evaluate the horizontal condylar guidance angle using protrusive interocclusal record at $6 \mathrm{~mm}$ distance from maximum intercuspation position using flat Lucia jig.
6. To compare the horizontal condylar guidance angle using protrusive interocclusal record using $4 \mathrm{~mm}$ and incisal edge to position of flat Lucia jig.

7. To compare the horizontal condylar guidance angle using protrusive interocclusal record using $4 \mathrm{~mm}$ and $6 \mathrm{~mm}$ of flat Lucia jig.

8. To compare the horizontal condylar guidance angle using protrusive interocclusal record at incisal edge to edge position (conventional method) with those obtained using $4 \mathrm{~mm}, 6 \mathrm{~mm}$ and incisal edge to edge position with flat Lucia jig.

\section{METHODS}

A cross sectional study was conducted on 21 completely dentulous participants (11 Females \& 10 males) aged, between 20 and 40 years according to the inclusion and exclusion criteria, from December 2020 to February 2021 at Yenepoya dental college, Mangalore

Inclusion criteria included participants having full complement of natural teeth with class I molar relation, no history of orthodontic therapy, periodontally healthy and caries free teeth with no sign of alveolar bone loss and pathologic migration and subjects exhibiting an average degree of horizontal and vertical overlap.

Exclusion criteria included any physical or psychological illnesses preventing the attachment of a facebow for registration purposes, symptoms indicative of muscular and temporomandibular disorders and if any progressive periodontal disease, major restorations, gross attritions. Subjects with pathological migration, traumatic occlusion of anterior teeth, temporomandibular joint clicking, crepitation, tenderness, and gross edentulism. Subjects associated with risk of radiation, like pregnancy, xerostomia, skin reactions, mucositis were also excluded.

\section{Ethical Statement}

Ethical clearance was obtained from the Yenepoya ethics committee - 2 (DCGI reg no: ECR / 1337 / Inst / KA / 2020) protocol no YEC2 / 510. All subjects included in the study were screened through a detailed case history and were wellinformed regarding the study design. Written consent from each subject was obtained.

Maxillary and mandibular primary impressions were made using irreversible hydrocolloid impression material (Zhermack Hydrorise, Italy) with rim lock trays (VISA) (Figure $1 \mathrm{a}, 1 \mathrm{~b}$ ). Casts were made using type IV die stone (Pearlstone, Asian Chemicals, India) according to manufacturer's recommendations. The casts were retrieved from the impression and excess was trimmed using model trimmer (Renfert, Germany) and base was made for the casts. Facebow record was obtained using arbitrary type HANAU ${ }^{\mathrm{TM}}$ Springbow (Whipmix, USA).

The bite fork was prepared with impression compound (Pinnacle) held at 3 position to orient the maxillary arch of each patient. The small bead of impression compound was 
kept in midline, the remaining 2 beads of compound were kept on either side of bite fork in the molar region.
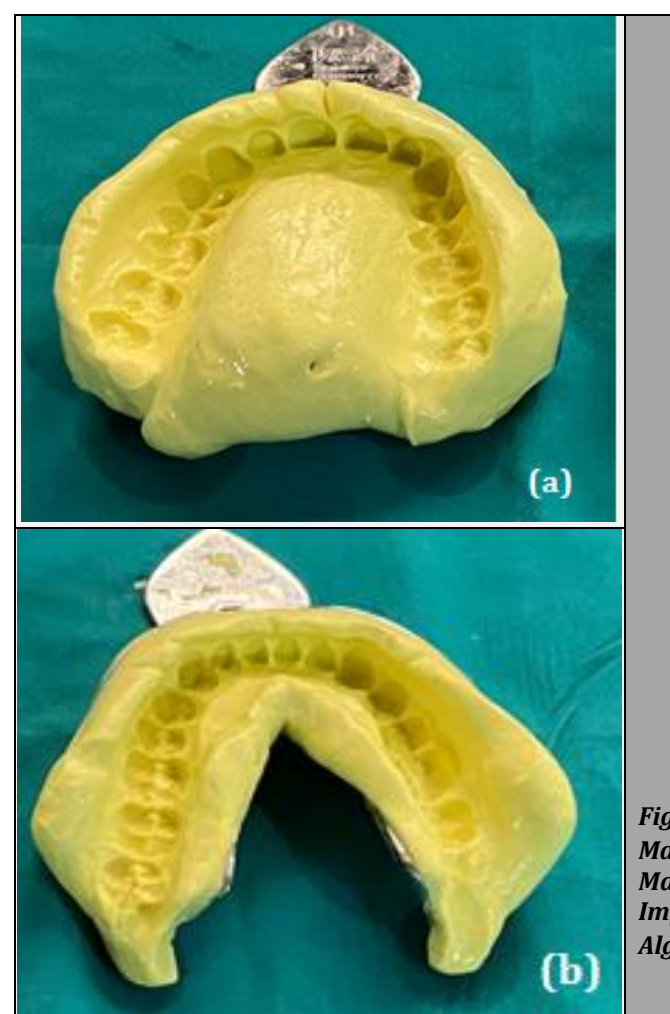

Figure 1a, $1 b$ Maxillary and Mandibular Impressions Usin

(b) Alginate

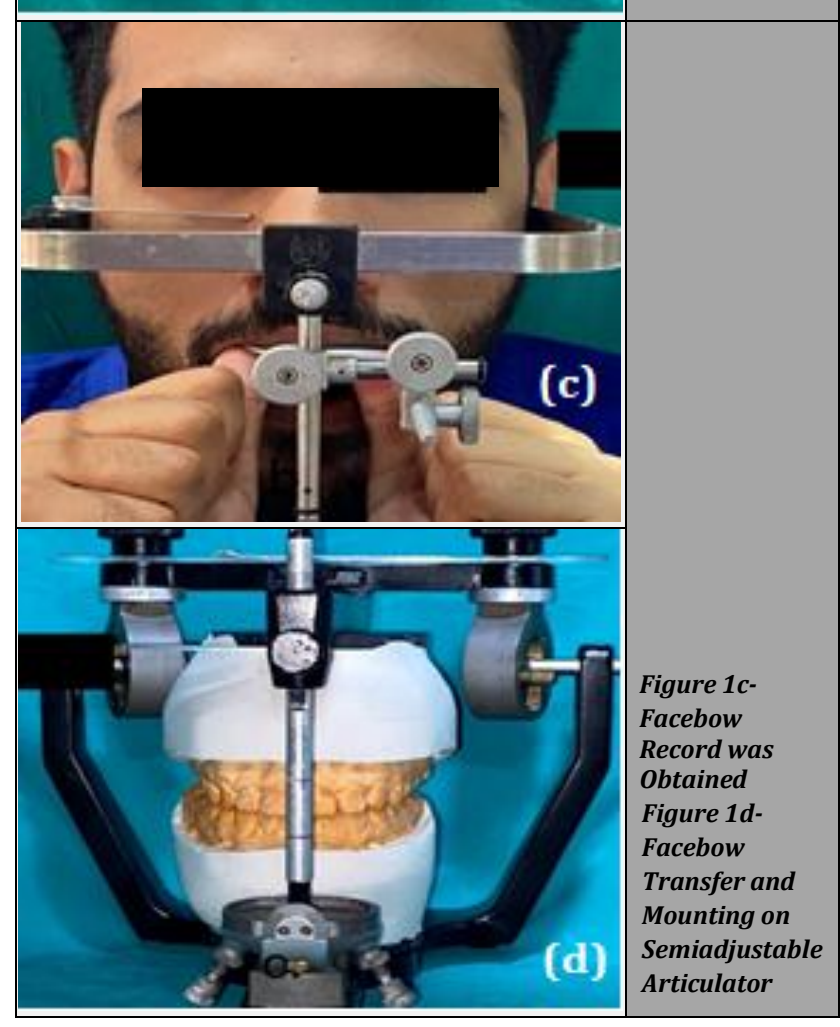

The U - shaped frame of ear piece type facebow was held in position. Bite fork was kept in mouth and using 3D joint $U$ shaped frame and bite fork were attached (Figure 1c). It was transferred to semi-adjustable HANAU ${ }^{\mathrm{TM}}$ H2 Wide-Vue Articulator (Whipmix, USA).
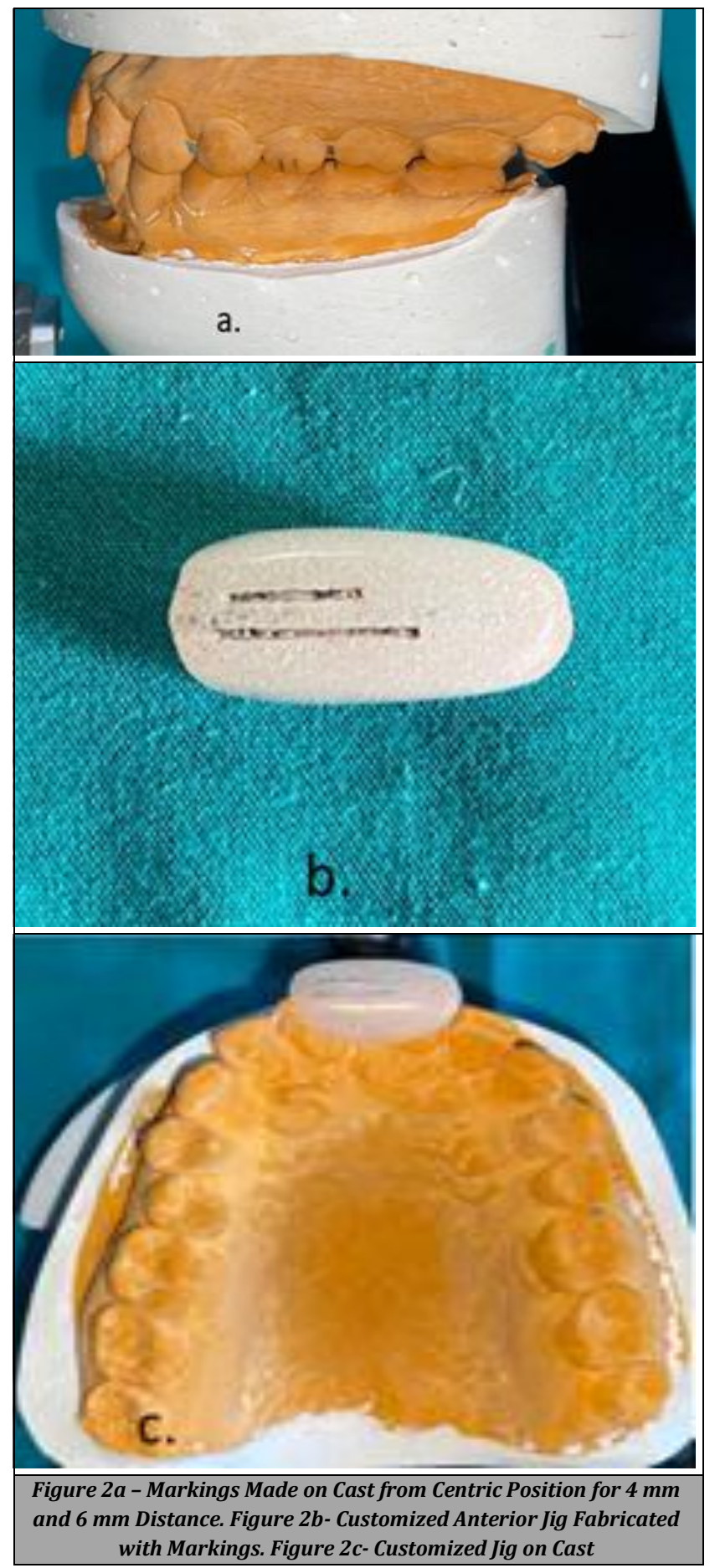

Zeroing of the semi-adjustable articulator was done before mounting. The incisal guide table was set to zero degrees, the horizontal condyle thumbnut was loosened and set to 30 degrees on both sides.

Similarly, the bennet angle was set to 30 degrees. The incisal rod was kept at the $6^{\text {th }}$ position on the markings. Once set, direct mounting of maxillary cast was done after attaching the facebow to the semi-adjustable articulator using dental plaster according to manufacturer's instructions on the semi adjustable articulator.

The lower cast was mounted using dental plaster at maximum intercuspation with the opposing mounted cast on the articulator and was allowed to set. Once set excess plaster was removed and polished (Figure 1d). 


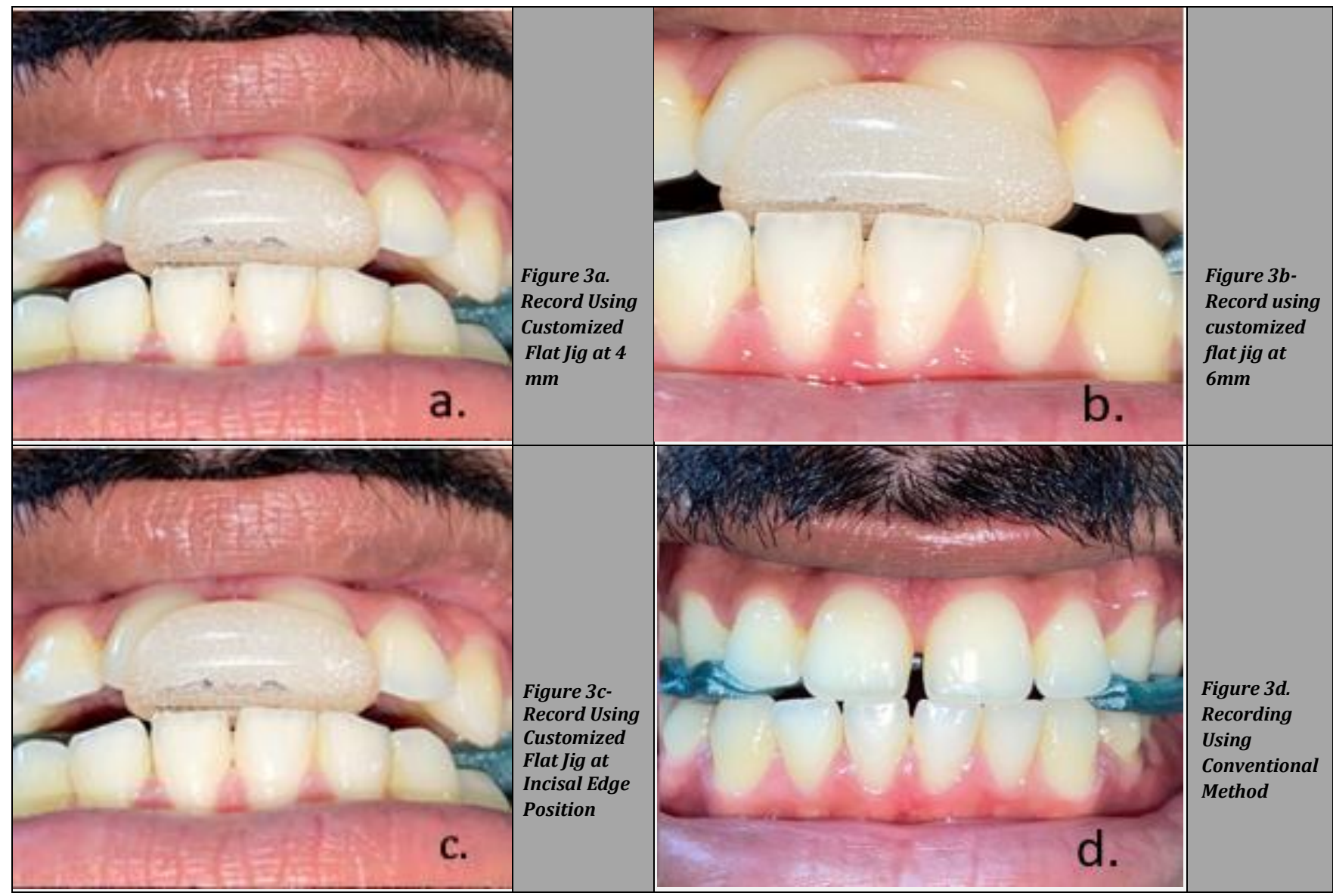

The mounted casts were now prepared for fabrication of flat anterior customized jig for each subject. The separating media was applied on the maxillary cast and was allowed to set for 10 minutes. A custom fabricated flat anterior jig was fabricated using self-cure clear acrylic resin (DPI, India). The clear acrylic monomer and polymer were mixed using a dappen dish and waited till it came to dough stage.

The material was molded and was flown on to the anterior 2 central incisors and adapted gently. It was allowed to set for 20 minutes. The excess acrylic material was trimmed using acrylic trimming bur. The occlusal surface was made flat to abolish the influence of anterior teeth. The flat customized anterior jig was polished using pumice for better visibility of teeth. The marking was made on the mounted cast at maximum intercuspation (Figure 2a).

From this point the $4 \mathrm{~mm}$ and $6 \mathrm{~mm}$ distance was marked on the cast. Keeping this as a reference the flat customized anterior jig was kept in positing and centric locks were loosened for easy movement of the upper member of the Hanau articulator.

The markings at $4 \mathrm{~mm}$ and $6 \mathrm{~mm}$ and incisal edge to edge position was made on the flat jig with the reference marking on the cast using articulating paper.

Now with this point the three notches were made on the flat anterior jig at a distance of $4 \mathrm{~mm}, 6 \mathrm{~mm}$ and at incisal edge to edge position from maximum intercuspation using a round bur extending on either side of the jig (Figure $2 b$ ). The jig was kept on the mounted articulator to evaluate if the grooves acted as a stop during movement of the mandible at varying distances (Figure 2c).
Protrusive interocclusal records were made using Alu wax (Maarc dental, India) by keeping flat customized anterior jig at a distance of $4 \mathrm{~mm}, 6 \mathrm{~mm}$ and incisal edge to edge relation (Figure 3a, 3b, 3c). Similarly, protrusive interocclusal record was obtained with incisal edge to edge relation without a flat jig (conventional method) (Figure 3d). The programming of the HANAU $^{\mathrm{TM}} \mathrm{H} 2$ Wide-Vue Articulator was done using protrusive interocclusal record material obtained using a flat jig at $4 \mathrm{~mm}, 6 \mathrm{~mm}$ and incisal edge to edge relation and incisal edge to edge position without flat jig to obtain the horizontal condylar guidance right and left side. The readings were recorded. The following procedure was done for all the subjects.

\section{Statistical Analysis}

Statistical analysis was performed using SPSS version 23. Data obtained from 21 samples were subjected to one - way ANOVA test and Pearson's correlation test to compare the right and left sides and to correlate horizontal condylar guidance angle obtained for 4 groups.

\section{RESULTS}

Mean horizontal condylar guidance angle obtained at varying interincisal distances on right side at incisal edge to edge (conventional) was 35.28. The mean values obtained for flat jig at incisal edge, flat jig at $4 \mathrm{~mm}$ and flat jig at $6 \mathrm{~mm}$ was 33.04 , 33.38 and 34.95 degrees, respectively. Similarly, for left side at incisal edge to edge (Conventional) was 36.66. The mean 
values obtained for flat jig at incisal edge, flat jig at $4 \mathrm{~mm}$ and flat jig at $6 \mathrm{~mm}$ was 32.61, 32.66 and 35.81 degrees, respectively. (Table 1 )

Pearson correlation test was done to compare if any corelation existed for horizontal condylar guidance angle between conventional and varying interincisal position. The results showed statistically significant difference for flat jig at incisal edge to edge, flat jig at $4 \mathrm{~mm}$ and flat jig at $6 \mathrm{~mm}$ on comparison with incisal edge to edge (Conventional).

The mean values obtained from the at incisal edge to edge (Conventional), flat jig at incisal edge, flat jig at $4 \mathrm{~mm}$ and flat jig at $6 \mathrm{~mm}$ distances provided good Pearson correlation values for the right $(R=0.773$ flat jig at incisal edge, $R=0.779$ flat jig at $4 \mathrm{~mm}, \mathrm{R}=0.632$ flat jig at $6 \mathrm{~mm}$ ) as well as the left side $(R=0.631$ flat jig at incisal edge, $R=0.601$ flat jig at $4 \mathrm{~mm}$, $\mathrm{R}=0.545$ flat jig at $6 \mathrm{~mm}$ ) when compared with the conventional incisal edge to edge values. This indicates strong level of positive corelation between the values obtained at varying interincisal distances and conventional method values which was statistically significant. ( Table 2)

\begin{tabular}{|c|c|c|c|c|}
\hline Side & Variables & Mean \pm SD & $\mathbf{F}$ & P Value \\
\hline \multirow{4}{*}{ Right } & Conventional & $35.28 \pm 11.36$ & \multirow{4}{*}{0.285} & \multirow{4}{*}{0.836} \\
\hline & Flat jig at incisal edge & $33.04 \pm 8.78$ & & \\
\hline & Flat jig at $4 \mathrm{~mm}$ & $33.38 \pm 8.54$ & & \\
\hline & Flat jig at $6 \mathrm{~mm}$ & $34.95 \pm 9.40$ & & \\
\hline \multirow{4}{*}{ Left } & Conventional & $36.66 \pm 12.92$ & \multirow{4}{*}{0.661} & \multirow{4}{*}{0.578} \\
\hline & Flat jig at edge & $32.61 \pm 11.74$ & & \\
\hline & Flat jig at $4 \mathrm{~mm}$ & $32.66 \pm 11.54$ & & \\
\hline & Flat jig at $6 \mathrm{~mm}$ & $35.81 \pm 11.17$ & & \\
\hline \multicolumn{5}{|c|}{$\begin{array}{c}\text { Table 1. Comparison of Right and Left Horizontal Condylar Guidance } \\
\text { Angles Obtained in Degrees at Different Interincisal Position for Right } \\
\text { and Left Side. P Value is Significant at } 0.05 \text { Level }\end{array}$} \\
\hline
\end{tabular}

\begin{tabular}{|c|c|c|c|c|c|}
\hline \multirow[b]{2}{*}{ Control } & \multirow[b]{2}{*}{$\begin{array}{c}\text { Test } \\
\text { Variables }\end{array}$} & \multicolumn{2}{|l|}{ Right } & \multicolumn{2}{|l|}{ Left } \\
\hline & & $\begin{array}{c}\text { Pearson } \\
\text { Correlation }\end{array}$ & P Valu & $\begin{array}{l}\text { Pearson } \\
\text { Correlation }\end{array}$ & ${ }_{n}$ P Value \\
\hline Conventional method & $\begin{array}{c}\text { Flat jig at } \\
\text { incisal edge }\end{array}$ & 0.773 & 0.000 & 0.631 & 0.002 \\
\hline (Incisal edge to edge) & Flat jig at $4 \mathrm{~mm}$ & 0.779 & 0.000 & 0.601 & 0.004 \\
\hline & Flat jig at $6 \mathrm{~mm}$ & 0.632 & 0.002 & 0.545 & 0.011 \\
\hline
\end{tabular}

\section{DISCUSSION}

Prosthetic dentistry aims at replacing the missing teeth with accurate records of centric and eccentric positions to articulate, fabricate and deliver a prosthesis that maintains harmony in the stomatognathic system.

There are divergent schools of thought in the literature, the first advocating that there is no influence of anterior determinant on horizontal condylar guidance whereas the second defend this agreement. ${ }^{10}$ The anterior determinants are teeth based on overjet and overbite, tooth morphology, and angulation of cusps. The posterior determinants are the inclination of condyles on both the right and left sides.

The first group advocates that no correlation exists between horizontal condylar guidance and anterior guidance. Pelletier and Campbell found no evidence of a connection between the condylar and anterior guidance. ${ }^{11,12}$ According to these authors, anterior guidance must be reconstructed and reorganized based on anatomical, aesthetic, and phonetic requirements so that a posterior disclusion can be achieved.

Similarly, the idea of a connection between anterior inclination paths and the morphology of the articular condylar surfaces was rejected by Alsawaf, et al. and Ingervall, who claimed that the ability of condylar rotation during translation helps the TMJ to adjust to different anterior inclination paths freely and without restriction. 13,14

The second school of thought asserts that the anterior slope and the condylar inclination direction are connected in same way. The gnathologic approach (McCollum and Stuart) described an anterior inclination path that was determined by the condylar inclination path, which contradicted the Pankey Mann - Schuyler concept (P. M. S.) ${ }^{11}$

Ogawa et al. reported that incisal guidance varies from individual to individual based on tooth morphology. Using a 3D mandibular movement analyzing system, he created protrusive interocclusal records in young adults. The impact of incisal and condylar guidance on the protrusive movement path varies depending on the type of tooth and the gender of the subject, according to the findings. ${ }^{[8]}$ Similarly, Takayama and Hobo suggested a statistically significant relationship between the anterior guidance path and the condylar path. $15,16,17$

As literature gives conflicting evidence regarding anterior guidance and horizontal condylar guidance, this study was done to evaluate the influence of anterior determinant on horizontal condylar guidance angle on each subject at varying mandibular positions with and without the flat customized jig.

Singh et al. determined and correlated the horizontal condylar guidance in individuals with Angle's Class I, Class II, and Class III malocclusion using radiographic (lateral cephalogram) and protrusive interocclusal records which were made at a distance of $6 \mathrm{~mm}$ using polyvinyl siloxane (PVS) bite registration paste. It was concluded that the average value of horizontal condylar guidance should not be used as it differs according to the skeletal relationship. ${ }^{18}$

However, they did not show the influence of anterior determinants on horizontal condylar guidance. Hence in this study, we eliminated the influence of anterior determinants by giving a customized flat jig in which the protrusive interocclusal records were obtained at varying interincisal distances.

The notches were made on the jig at a distance of $4 \mathrm{~mm}, 6$ $\mathrm{mm}$ and incisal edge to edge distance from maximum intercuspation. The protrusive records were obtained at varying interincisal distances with the help of these notches using wax interocclusal records. These records were used to set horizontal condylar guidance angles using a semiadjustable articulator.

There was a statistically significant positive correlation at $\mathrm{P}$ - value $\leq 0.05$ among conventional methods on comparison with a flat jig at the incisal edge to edge, flat jig at $4 \mathrm{~mm}$, and flat jig at $6 \mathrm{~mm}$. Therefore, the null hypothesis which stated that the protrusive interocclusal records taken with and without the influence of anterior guidance has no effect on horizontal condylar guidance angle in dentulous patients and was rejected.

Among the clinical methods, values obtained from the flat jig method obtained at varying distances exhibited a good level of association with that of a conventional method for both the right and left sides. Overall, this indicates a strong level of association with those obtained at the conventional method.

Based on the results of this study clinicians should consider the use of flat custom jig while obtaining the protrusive interocclusal records thus eliminating various tooth morphology (anterior determinant). However, further 
studies with larger sample sizes are required to confirm the results of the present study.

\section{CONCLUSIONS}

Within the limitations of the study, it can be concluded that the horizontal condylar guidance angle is influenced by anterior determinant i.e., patient overjet and overbite will influence horizontal condylar guidance recorded by using protrusive interocclusal records. The reliability of protrusive records obtained to set horizontal condylar guidance is dependent on eliminating the influence of anterior determinant.

Data sharing statement provided by the authors is available with the full text of this article at jemds.com.

Financial or other competing interests: None.

Disclosure forms provided by the authors are available with the full text of this article at jemds.com.

\section{REFERENCES}

[1] Goyal MK, Goyal S. A comparative study to evaluate the discrepancy in condylar guidance values between two commercially available arcon and non-arcon articulators: a clinical study. Indian J Dent Res 2011;22(6):880.

[2] Koyano K, Tsukiyama Y, Kuwatsuru R. Rehabilitation of occlusion-science or art? J Oral Rehabil 2012;39(7):51321.

[3] Godavarthi AS, Sajjan MS, Raju AR, et al. Correlation of condylar guidance determined by panoramic radiographs to one determined by conventional methods. J Int Oral Health 2015;7(8):123-8.

[4] Christensen LV, Slabbert JC. The concept of the sagittal condylar guidance: biological fact or fallacy? J Oral Rehabil 1978;5(1):1-7.

[5] Posselt UP, Franzen G. Registration of the condyle path inclination by intraoral wax records: variations in three instruments. J Prosthet Dent 1960;10(3):441-54.
[6] Craddock FW. The accuracy and practical value of records of condyle path inclination. J Am Dent Assoc 1949;38(6):697-710.

[7] Pound E. The mandibular movements of speech and their seven related values. J Prosthet Dent 1966;16(5):835-43.

[8] Ogawa T, Koyano K, Suetsugu T. The influence of anterior guidance and condylar guidance on mandibular protrusive movement. J Oral Rehabil 1997;24(4):303-9.

[9] Schlosser RO. Complete denture prosthesis. $2^{\text {nd }}$ edn. Philadelphia: W. B. Saunders Company 1946.

[10] Zoghby AE, Re JP, Perez C. Functional harmony between the sagittal condylar path inclination and the anterior guidance inclination. Int $\mathrm{J}$ Stomat Occ Med 2009;2(3):131-6.

[11] Pelletier LB, Campbell SD. Evaluation of the relationship between anterior and posterior functionally disclusive angles. Part I: literature review, instrumentation and reproducibility. J Prosthet Dent 1990;63(4):395-403.

[12] Pelletier LB, Campbell SD. Evaluation of the relationship between anterior and posterior functionally disclusive angles. Part II: study of a population. J Prosthet Dent 1990;63(5):536-40.

[13] Alsawaf MM, Garlapo DA. Influence of tooth contact on the path of condylar movements. J Prosthet Dent 1992;67(3):394-400.

[14] Ingervall B. Range of sagittal movement of the mandibular condyles and inclination of the condyle path in children and adults. Acta Odontol Scand 1972;30(1):67-87.

[15] Hobo S. Twin-tables technique for occlusal rehabilitation: part I-mechanism of anterior guidance. J Prosthet Dent 1991;66(3):299-303.

[16] Hobo S. Twin-tables technique for occlusal rehabilitation: part II-clinical procedures. J Prosthet Dent 1991;66(4):471-7.

[17] Takayama H, Hobo S. Kinematical and experimental analyses of the mandibular movement for clinical application. Int J Sys 1984;2:229-304.

[18] Singh S, Das S, Bhattacharyya J, et al. A comparative study to correlate between clinically and radiographically determined sagittal condylar guidance in participants with different skeletal relationships. J Indian Prosthodont Soc 2017;17(2):175-82. 